\title{
NARCOTIC DISCRIMINATION IN PIGEONS: ANTAGONISM BY NALTREXONE
}

\author{
SEYMORE HERLING *, RITA J. VALENTINO **, ROBERT E. SOLOMON *** and JAMES H. WOODS \\ Departments of Pharmacology and Psychology, University of Michigan, Ann Arbor, Michigan 48109, U.S.A. and Clinical Institute, \\ Addiction Research Foundation, Toronto, Ontario, Canada
}

Received 27 June 1984, accepted 9 July 1984

S. HERLING, R.J. VALENTINO, R.E. SOLOMON and J.H. WOODS, Narcotic discrimination in pigeons: Antagonism by naltrexone, European J. Pharmacol. 105 (1984) 137-142.

In pigeons trained to discriminate between morphine $(10 \mathrm{mg} / \mathrm{kg})$ and saline, both morphine and ethylketazocine produced dose-related morphine-appropriate responding. The maximum effect produced by meperidine, however, was only $60 \%$ of that produced by morphine or ethylketazocine. Naltrexone $(0.1-1.0 \mathrm{mg} / \mathrm{kg})$ produced dose-related shifts to the right in the dose-response curves for the discriminative stimulus and rate-decreasing effects of morphine and ethylketazocine without affecting the response produced by meperidine. Thus, in contrast to the effects observed in other species, morphine and ethylketazocine produce similar discriminative effects in the pigeon. In addition, the morphine-like discriminative effects and the rate-decreasing effects of meperidine in the pigeon are not mediated by the naltrexone-sensitive mechanisms which mediate these effects of morphine or ethylketazocine.

Morphine Ethylketazocine Meperidine Drug discrimination Antagonism Pigeons

\section{Introduction}

Several lines of evidence suggest that many of the effects of ethylketazocine and other $\kappa$-receptor agonists in several species are mediated by a receptor that differs from that mediating the effects of morphine (a $\mu$-receptor agonist) (Woods et al., 1978; Iwamoto and Martin, 1981; Wood, 1982). Results of drug discrimination studies are consistent with this concept (Herling and Woods, 1981). For example, in rats or squirrel monkeys trained to discriminate between morphine and saline, neither ketazocine nor ethylketazocine substitutes for morphine as a discriminative stimulus (Shannon and Holtzman, 1977; Teal and Holtz-

* To whom all correspondence should be addressed: Addiction Research Foundation, 33 Russell Street, Toronto, Ontario, Canada M5S 2S1.

** Present address: Department of Pharmacology, George Washington University Medical Center, 2300 Eye Street NW, Washington, D.C. 20037, U.S.A.

*** Present address: University of Iowa College of Medicine, Iowa City, IA 52242, U.S.A. man, 1980; Schaefer and Holtzman, 1981). In the pigeon, however, morphine, ethylketazocine, and ketazocine appear to share discriminative stimulus effects, since each of these drugs produces dose-related drug-appropriate responding in pigeons trained to discriminate between either morphine or ethylketazocine and saline (Herling and Woods, 1981).

Additional evidence that the behavioral effects of morphine and ethylketazocine in certain species are mediated by different mechanisms is derived from studies on the antagonism of these effects by naloxone or naltrexone. In rats, for example, the effects of ketazocine and ethylketazocine on schedule-controlled responding are more difficult to antagonize by naltrexone than are similar effects of morphine (Harris, 1980). More recently, Leander (1982) has shown that the effects of phenazocine (a proposed $\mu$ agonist) on schedule-controlled responding in the pigeon were also reversed by considerably smaller doses of naloxone (0.01-1.0 $\mathrm{mg} / \mathrm{kg}$ ) than were comparable effects of either ethylketazocine or ketazocine. Thus, in contrast to 
the discriminative effects of ethylketazocine and ketazocine in the pigeon, which on the basis of cross-generalization results were suggested to be mediated similarly to the discriminative effects of $\mu$ agonists (Herling and Woods, 1981), the response rate-decreasing effects of ethylketazocine and ketazocine in the pigeon appear to be mediated differently than the rate-decreasing effects of $\mu$ agonists (Leander, 1982).

The purpose of the present experiment was to compare the ability of the narcotic antagonist naltrexone to antagonize the discriminative stimulus and rate-decreasing effects of morphine and ethylketazocine in the pigeon to determine if different behavioral effects of these drugs are mediated differently. In addition, the ability of naltrexone to antagonize the discriminative and rate-decreasing effects of meperidine was determined. As a discriminative stimulus, meperidine substitutes only partially for morphine in the pigeon (Herling et al., 1980), and whereas the response rate-increasing effects of lower doses of meperidine are antagonized by naloxone, the response rate-decreasing effects of higher doses of meperidine are not (Leander and McMillan, 1977). Thus, whether the partial morphine-like discriminative effects of meperidine might be blocked by naltrexone was assessed.

\section{Materials and methods}

The subjects were four White Carneaux pigeons maintained at approximately $80 \%$ of free-feeding weight. These pigeons had served as subjects in an earlier morphine discrimination experiment (Herling et al., 1980).

Experimental sessions were conducted in chambers that have been described in detail previously (Herling et al., 1980). Briefly, the inside front panel of each chamber contained two translucent response keys that were transilluminated during experimental sessions by red 7-W lights. Food (mixed grain) could be presented to the pigeon through a rectangular opening located below the keys. During training sessions, each pigeon was required to emit 20 consecutive responses on one of two keys to produce 4-s access to food. The key on which responses produced food was determined by the i.m. presession injection of either $10 \mathrm{mg} / \mathrm{kg}$ morphine (left key) or saline (right key). Responses on the inappropriate key reset the response requirement on the appropriate key. Sessions ended after 32 food deliveries or $1 \mathrm{~h}$, whichever occurred first. Training sessions were conducted 6 days per week with morphine and saline injections alternating from one session to the next.

Once the training criteria were met (refer to Herling et al., 1980 for details), test sessions were conducted with morphine, ethylketazocine, or meperidine, alone or in combination with naltrexone. During test sessions, 20 consecutive responses on either the morphine- or saline-appropriate key resulted in food delivery; in all other respects, test sessions were identical to training sessions.

Morphine sulfate (Mallinckrodt Chemical Works, St. Louis, MO), meperidine hydrochloride (Sterling-Winthrop Research Institute, Rensselaer, NY) and naltrexone hydrochloride (Endo Laboratories, Garden City, NY) were dissolved in $0.9 \%$ sterile saline. Ethylketazocine methane sulfonate (Sterling-Winthrop Research Institute) was dissolved in sterile water to which a small amount of lactic acid was added; sodium hydroxide was used to adjust the $\mathrm{pH}$ above 3 . All drugs were injected i.m., usually in a volume of $1 \mathrm{ml} / \mathrm{kg}, 10 \mathrm{~min}$ before the start of the session. When drug combinations were studied, naltrexone was injected into the breast muscle on one side of the animal, followed immediately by an injection of morphine, ethylketazocine or meperidine into the breast muscle on the opposite side.

The data for test sessions are presented as the average number of responses throughout the session that were emitted on the morphine-appropriate key, expressed as a percentage of the total responses. The overall rate of responding on the two keys was also recorded during each session. The average rate of responding after drug injection is expressed as a percentage of the previous saline control rates. 


\section{Results}

Morphine and ethylketazocine, when administered alone, produced dose-related increases in the percentage of responses emitted on the morphineappropriate key (fig. 1, upper panels: closed circles). Morphine doses of $10 \mathrm{mg} / \mathrm{kg}$ and higher and ethylketazocine doses of $3 \mathrm{mg} / \mathrm{kg}$ and higher resulted in greater than $90 \%$ morphine-appropriate responding in each pigeon. Meperidine also produced dose-related morphine-appropriate responding, but the average maximum effect, which occurred at $5.6 \mathrm{mg} / \mathrm{kg}$, was only $60 \%$ of the maximum effect produced by morphine or ethylketazocine (fig. 2, upper panel: closed circles). All three drugs produced dose-related decreases in the rate of responding (figs. 1 and 2, lower panels: closed circles). The lowest doses of morphine, ethylketazocine, and meperidine which produced maximum morphine-appropriate responding, reduced response rates by approximately 20,30 and $50 \%$, respectively.

Naltrexone $(0.1-1.0 \mathrm{mg} / \mathrm{kg})$ shifted the dose-ef- fect curves for the discriminative effects of morphine and ethylketazocine to the right (fig. 1, upper panels). The minimum doses of morphine and ethylketazocine required to produce at least $90 \%$ morphine-appropriate responding were shifted to the right by $0.1 \mathrm{mg} / \mathrm{kg}$ of naltrexone approximately 6 -fold and 19 -fold, respectively. In the presence of $1.0 \mathrm{mg} / \mathrm{kg}$ of naltrexone, doses of morphine or ethylketazocine up to $100 \mathrm{mg} / \mathrm{kg}$ produced less than 55\% morphine-appropriate responding. Naltrexone also shifted the dose-effect curves for the rate-decreasing effects of morphine and ethylketazocine to the right (fig. 1, lower panels). The shifts in dose-effect curves for the rate-decreasing effects of morphine and ethylketazocine were less pronounced than the shifts for the discriminative effects of the drugs. Doses of morphine and ethylketazocine required to produce a $50 \%$ decrease in response rate were shifted to the right by $0.1 \mathrm{mg} / \mathrm{kg}$ of naltrexone approximately 1.5 - and 4.0 -fold, respectively.

In contrast to the effects of morphine and ethylketazocine, neither the discriminative stimulus
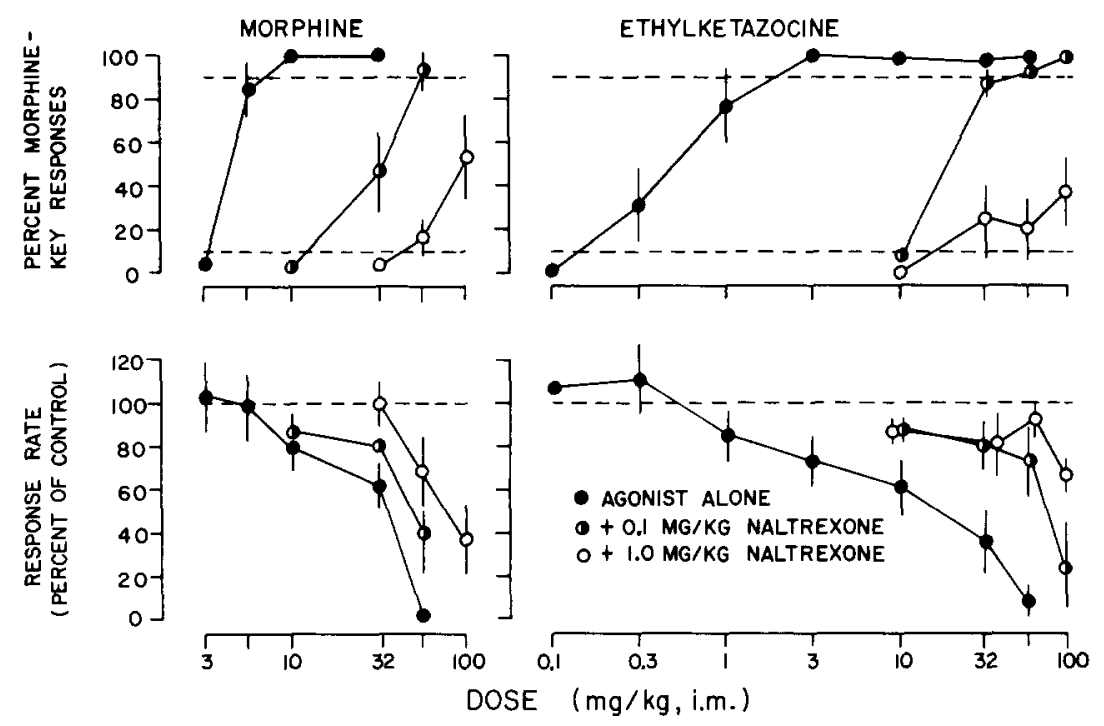

Fig. 1. Dose-effect curves for morphine and ethylketazocine, administered either alone (closed circles) or in the presence of 0.1 (half-filled circles) or 1.0 (open circles) $\mathrm{mg} / \mathrm{kg}$ of naltrexone. Upper panel ordinates: average number of responses emitted on the morphine-appropriate key, expressed as a percentage of the total session responses. Lower panel ordinates: average rate of responding after drug injection, expressed as a percentage of the rate of responding following saline injection. Average absolute response rates in individual pigeons ranged from 1.4-4.1 responses/s. Abscissae: dose of morphine or ethylketazocine, in mg/kg. Each point represents the mean of one observation in each of four pigeons. Vertical lines through the points indicate \pm 1 S.E.M. 

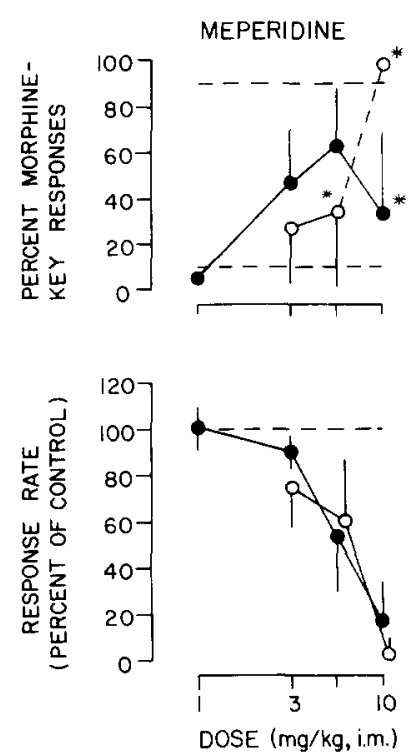

Fig. 2. Dose-effect curves for meperidine, administered either alone (closed circles) or in the presence of $1.0 \mathrm{mg} / \mathrm{kg}$ of naltrexone (open circles). Ordinates as in fig. 1. Abscissae: dose of meperidine, in $\mathrm{mg} / \mathrm{kg}$. * One out of four pigeons did not respond following the administration of $10 \mathrm{mg} / \mathrm{kg}$ of meperidine alone or following the combination of $5.6 \mathrm{mg} / \mathrm{kg}$ of meperidine and $1.0 \mathrm{mg} / \mathrm{kg}$ of naltrexone. Three out of four pigeons did not respond following the administration of 10 $\mathrm{mg} / \mathrm{kg}$ of meperidine and $1.0 \mathrm{mg} / \mathrm{kg}$ of naltrexone. Other details as in fig. 1.

nor rate-decreasing effects of meperidine were antagonized by naltrexone (fig. 2). Only one out of four pigeons was able to respond following the combination of $1.0 \mathrm{mg} / \mathrm{kg}$ of naltrexone and 10 $\mathrm{mg} / \mathrm{kg}$ of meperidine and this bird emitted over $98 \%$ morphine-appropriate responses both in the presence and absence of naltrexone administration.

\section{Discussion}

Both morphine and ethylketazocine produced dose-related drug-appropriate responding in pigeons trained to discriminate between morphine and saline. These results are consistent with previous observations in the pigeon on the similarity between the discriminative effects of so-called $\mu$ agonists (e.g., morphine, fentanyl) and the dis- criminative effects of certain drugs (e.g., ethylketazocine, ketazocine) that are designated as $\kappa$ agonists (Herling and Woods, 1981; J.D. Leander, personal communiation). Thus pigeons appear to be different than certain other species in that, in these other species (e.g., rats, squirrel monkeys, rhesus monkeys), neither ethylketazocine nor ketazocine produces morphine- or fentanyl-like discriminative effects (e.g., Herling and Woods, 1981; Shearman and Herz, 1982).

In contrast to ethylketazocine, meperidine failed to produce stimulus control of responding similar to that produced by morphine. Likewise, meperidine, in the pigeon, does not produce fentanyl-appropriate responding (J.D. Leander, personal communiation). In rats, squirrel monkeys and rhesus monkeys, however, meperidine uniformly produces morphine- or fentanyl-like discriminative effects (Herling and Woods, 1981). Thus, in the pigeon, the discriminative stimulus effects of ethylketazocine, but not those of meperidine, are similar to the discriminative effects of morphine-like agonists; in certain other species, however, the converse appears to be true (cf. Herling and Woods, 1981).

Naltrexone antagonized the discriminative and rate-decreasing effects of morphine and ethylketazocine but was ineffective in blocking the effects of meperidine. These results agree with previous observations on the ability of naloxone or naltrexone to antagonize morphine or ethylketazocine in the pigeon (Jarbe, 1978; Herling et al., 1980; Valentino et al., 1981) and on the inability of naloxone to antagonize meperidine in this species (Leander and McMillan, 1977; Leander, 1979, 1980).

Interestingly, however, naltrexone shifted the dose-effect curves for the rate-decreasing effects of morphine and ethylketazocine 4-5 times less to the right than the dose-effect curves for their discriminative effects (fig. 1). This result suggests that different mechanisms may be involved in the discriminative and rate-decreasing effects of these drugs. Moreover, the dose-effect curves of ethylketazocine were shifted to the right by naltrexone more than the morphine dose-effect curves (fig. 1). The ability of narcotic antagonists to differentially antagonize similar behavioral effects of different 
agonists suggests differences in mechanisms of agonist activity (e.g., Leander and McMillan, 1977; Harris, 1980). Such may be the case for the effects of morphine and ethylketazocine in the pigeon. However, in contrast to the present study, Leander (1982) showed that the effects of phenazocine (a proposed $\mu$ agonist) on schedule-controlled responding in the pigeon were antagonized by lower doses of naloxone than were needed to antagonize similar effects of ethylketazocine and ketazocine.

The reasons for the discrepancy between our findings and those of Leander (1982) are not clear, differences between phenazocine and morphine as agonists and naloxone and naltrexone as antagonists notwithstanding. The pigeons used in the present experiment were likely tolerant to the effects of morphine as a result of chronic exposure to the morphine training dose (see Herling et al., 1980). The contribution of morphine tolerance to the effects of combined injections of different agonists and antagonists on schedule-controlled responding is largely unknown. Nor is it obvious that tolerance to the effects of morphine can account for the differences in the results of the present experiment and the findings of Leander (1982). Clearly what is needed is a more thorough analysis of interactions of narcotic agonists and antagonists on schedule-controlled responding.

In summary, the results of the present experiment indicate that, in the pigeon, both the discriminative and rate-decreasing effects of morphine and ethylketazocine are antagonized by naltrexone, whereas the discriminative and rate-decreasing effects of meperidine are not. This result suggests differences in the mechanisms of action of meperidine and both morphine and ethylketazocine. Secondly, differences in the extent to which dose-effect curves were shifted to the right by naltrexone suggest that, despite producing similar discriminative stimulus and rate-decreasing effects, the effects of morphine and ethylketazocine in the pigeon are mediated differently and, moreover, that different mechanisms may be involved in different behavioral (i.e., discriminative, rate-decreasing) effects of these drugs. The results of the present study, however, should be interpreted with caution. It is well known that the discriminative and rate-decreasing of drugs are influenced by a number of different experimental conditions (e.g., training dose, tolerance, the measures used to assess discriminative control); additional research evaluating these conditions is needed to assess the generality of the present findings.

\section{Acknowledgements}

This research was conducted at The University of Michigan and was supported by U.S. Public Health Service Grant DA 00154. Preparation of the manuscript was supported by the Addiction Research Foundation of Ontario. The helpful comments of Jonathan Katz on an earlier draft of this paper and the assistance of Isabel Herling in preparing the manuscript are gratefully acknowledged.

\section{References}

Harris, R.A., 1980, Interactions between narcotic agonists, partial agonists and antagonists evaluated by schedule-controlled behavior, J. Pharmacol. Exp. Ther. 213, 497.

Herling, S., E.H. Coale, Jr., R.J. Valentino, D.W. Hein and J.H. Woods, 1980, Narcotic discrimination in pigeons, J. Pharmacol. Exp. Ther. 214, 139.

Herling, S. and J.H. Woods, 1981, Discriminative stimulus effects of narcotics: Evidence for multiple receptor-mediated actions, Life Sci. 28, 1571.

Iwamoto, E.T, and W.R. Martin, 1981, Multiple opioid receptors, Med. Res. Rev. 1, 411.

Jarbe, T.U.C., 1978, Discriminative effects of morphine in the pigeon, Pharmacol. Biochem. Behav. 9, 411.

Leander, J.D., 1979, Meperidine as a drug cue in pigeons: Not a narcotic effect, Fed. Proc. 38, 863.

Leander, J.D., 1980, Comparison of morphine, meperidine, anileridine, and alphaprodine on schedule-controlled responding and analgesia, Pharmacol. Biochem. Behav. 12, 797.

Leander, J.D., 1982, Effects of ketazocine, ethylketazocine and phenazocine on schedule-controlled behavior: Antagonism by naloxone, Neuropharmacol. 21, 923.

Leander, J.D. and D.E. McMillan, 1977, Meperidine effects on schedule-controlled responding, J. Pharmacol. Exp. Ther. 201,434

Schaefer, G.J. and S.G. Holtzman, 1981, Morphine-like stimulus effects in the monkey: Opioids with antagonist properties, Pharmacol. Biocherm. Behav. 14, 241.

Shannon, H.E. and S.G. Holtzman, 1977, Further evaluation of the discriminative effects of morphine in the rat, J. Pharmacol. Exp. Ther. 201, 55.

Shearman, G.T. and A. Herz, 1982, Evidence that the discriminative stimulus properties of fentanyl and ethylketocyclazocine are mediated by an interaction with different opiate receptors, J. Pharmacol. Exp. Ther. 221, 735. 
Teal, J.J. and S.G. Holtzman, 1980, Discriminative stimulus effects of prototype opiate receptor agonists in monkeys, European J. Pharmacol. 68, 1.

Valentino, R.J., S. Herling, J.H. Woods, F. Medzihradsky and H. Merz, 1981, Quaternary naltrexone: Evidence for the central mediation of discriminative stimulus effects of narcotic agonists and antagonists, J. Pharmacol. Exp. Ther. 217,652 .
Wood, P.L., 1982, Multiple opiate receptors: Support for unique mu, delta and kappa sites, Neuropharmacol. 21, 487.

Woods, J.H., C.L. Fly and H.H. Swain, 1978, Behavioral actions of some $\mathrm{N}$-furyl benzomorphans and ketazocines in rhesus monkeys and mice, in: Characteristics and Function of Opioids, eds. J.M. Van Ree and L. Terenius (Elsevier/North Holland, Amsterdam) p. 403. 